Conclusions: Our data confirm that genetic polymorphism rs12218 in SAA1 gene, is associated with the development of secondary amyloidosis in RA patients and mutation in this gene is an important risk factor predisposing to the development of this severe complication in the Russian population.

Disclosure of Interest: None declared

DOI: 10.1136/annrheumdis-2018-eular.2465

\section{AB0272 MEAN PLATELET VOLUME AS A POTENTIAL BIOLOGICS THERAPY RESPONSE PREDICTOR AND DISEASE ACTIVITY INDICATOR IN PATIENTS WITH RHEUMATOID ARTHRITIS}

M. Čaić ${ }^{1}$, M. Mayer ${ }^{2} .{ }^{1}$ University of Zagreb, School of Medicine; ${ }^{2}$ Division of Clinical Immunology and Rheumatology, University Hospital Centre KBC Zagreb, Zagreb, Croatia

Background: Rheumatoid arthritis (RA) is a chronic systemic inflammatory disease that primarily affects joints. Currently, the most widely used markers of acute phase response are C-reactive protein (CRP) and erythrocyte sedimentation rate (ESR). However, in recent years it has been suggested that platelet histogram indices, such as mean platelet volume (MPV) could be predictors of disease activity in patients with RA.

Objectives: The aim of this study was to assess whether MPV can be used as a disease activity marker by analysing a possible correlation between MPV and DAS-28, serum CRP levels, and ESR in patients starting with or switching between different biological DMARDs (tocilizumab, infliximab). Finally, we investigate whether MPV value at baseline can be a therapy outcome predictor by comparing two groups of patients (remission and active disease) at the 12 month time point based on DAS-28 value.

Methods: Fifteen patients (aged $56.5 \pm 9.3$ years) fulfilling the American College of Rheumatology (ACR) criteria for RA were retrospectively enrolled in the study from the rheumatology outpatient clinic at the University Hospital Centre Zagreb, Croatia. DAS-28 has been used to evaluate disease activity at baseline, 3 months, 6 months, 9 months, and 12 months after starting biological DMARD therapy. Laboratory assessments included a complete blood count (including MPV), ESR, and CRP levels at each visit.

Results: We have observed a significant reduction in DAS-28 within the 12 month assessment period (from $5.33 \pm 1.24$ to $2.25 \pm 1.23$ ). MPV varied between $8.5 \pm 0.6$ at baseline and $9.0 \pm 0.8$ at the 12 month time point, with its peak being at the 9 month time point $(9.3 \pm 0.8)$. Mean MPV had an inverse correlation with mean DAS-28 $(r=-0.94, p=0.02)$, as well as mean ESR $(r=-0.91, p=0.03)$. A weaker correlation was observed with mean CRP $(r=-0.56, p=0.3)$.

When assessing whether MPV could be used as a therapy response predictor, patients were divided into two groups: those in remission at the 12 month time point $(n=10)$ and those with significant disease activity $(n=5)$, with remission being defined as a DAS-28 value of 2.8 or less. There was no significant difference in MPV values between those groups $(8.5 \pm 0.56$ for those in remission and 8.52 \pm 5.45 for those with active disease).

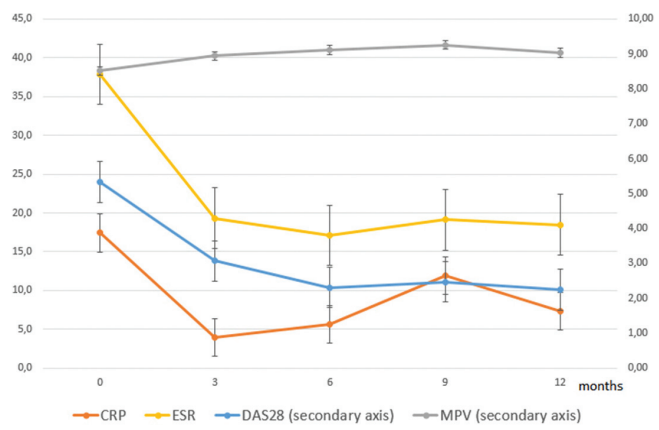

Abstract AB0272 - Figure 1

Conclusions: The results of this study provide additional evidence supporting the previously reported correlation between MPV and other disease activity markers (DAS-28, ESR) to treatment response in RA patients. It seems MPV isn't a viable therapy outcome predictor given that there is no significant difference in MPV value in patients in remission and those not in remission.

\section{REFERENCES:}

[1] Moghimi J, Ghahremanfard F, Salari M, Ghorbani R. Association between mean platelet volume and severity of rheumatoid arthritis. Pan Afr Med J. 2017;27:276. doi:10.11604/pamj.2017.27.276.12228
[2] Tecer D, Sezgin M, Kanık A, et al. Can mean platelet volume and red blood cell distribution width show disease activity in rheumatoid arthritis? Biomark Med. 2016;10(9):967-974. doi:10.2217/bmm-2016-0148

[3] Tekeoğlu I, Gürol G, Harman H, Karakeçe E, Çiftçi İH. Overlooked hematological markers of disease activity in rheumatoid arthritis. Int $\mathrm{J}$ Rheum Dis. 2016;19(11):1078-1082. doi:10.1111/1756-185X.12805

Disclosure of Interest: None declared

DOI: 10.1136/annrheumdis-2018-eular.7086

\section{AB0273 ASSESSMENT OF SERUM LEVELS OF 14-3-3H PROTEIN IN RHEUMATOID ARTHRITIS: IS IT A SPECIFIC MARKER FOR THE DISEASE?}

M. Elshahaly ${ }^{1}$, M. Saleh ${ }^{2}$, H. Fahmy ${ }^{2}$, M. Othman ${ }^{2} .{ }^{1}$ Rheumatology, physical medicine and rehabilitation; ${ }^{2}$ Clinical and Chemical Pathology, School of Medicine, Suez Canal University, Ismailia, Egypt

Background: $14-3-3 \eta$ protein was suggested to be significantly higher in serum and synovial fluid of rheumatoid arthritis (RA) patients compared to healthy individuals and other diseases such as osteoarthritis (OA) and ankylosing spondylitis (AS). ${ }^{1}$ Accordingly, $14-3-3 \eta$ is now thought to be a diagnostic marker for early RA. Furthermore, some reports suggest that it correlates well with disease activity. ${ }^{2}$

Objectives: To assess the usefulness of serum levels of $14-3-3 \eta$ protein in the diagnosis of RA in comparison with hands OA patients and healthy controls; furthermore, to correlate its levels with markers of inflammation in RA patients.

Methods: This study was carried out as a case control comparative study. Our sample consisted of three groups. Group 1 was made up of 30 RA patients fulfilling 2010 ACR-EULAR classification criteria for RA; ${ }^{3}$ Group 2 made up of 30 hands OA patients according to OA ACR criteria ${ }^{4}$ and group 3 of 30 healthy volunteers. Patients with other rheumatic and/or systemic diseases or infections were excluded.

Patients were assessed using detailed clinical history and examination. Laboratory investigations included complete blood picture, ESR, CRP, RF, ACPA and serum levels of $14-3-3 \eta$ protein using manual enzyme-linked immunosorbent assay (ELISA).

Results: Mean (SD) age of RA group was 45.5 (9.5) years old; for OA group was 50.3 (8.8) years old, and the control group was 46.2 (6.9) years old. Females represented $96.7 \%$ of group $1 ; 83.3 \%$ of group 2 , and $86.7 \%$ of group 3 . RF was positive in $78 \%$ of RA group, $6.7 \%$ in OA group and $6.3 \%$ of control group. Mean (SD) of RF titer was 123 (10.3), 15.3 (5.4) and 14.4 (5.2) IU/ml respectively. ACPA was positive in $96.7 \%$ of group 1 and was negative in groups 2 and 3 . Mean (SD) ACPA was 64.4 (6.6) $\mathrm{U} / \mathrm{ml}$ in RA group.

Mean (SD) ESR was 32.5 \pm 8.2 in group 1, $22.0(6.6)$ in group 2 and $16.1(7.3) \mathrm{mm} /$ hour in group 3. Mean (SD) CRP was 17.9 (5.04), 5.7 (2.8) in group 2 and $4.9(2.4)$ $\mathrm{mg} / \mathrm{L}$ in group 3 .

Mean (SD) levels of $14-3-3 \eta$ protein were significantly higher among RA com pared to OA and control groups (3.63 (1.35), $0.23(0.14)$ and $0.28(0.08) \mathrm{ng} / \mathrm{ml}$, respectively) $(p<0.0001)$.

The optimal cutoff point of $14-3-3 \eta$ protein to diagnose RA was $>0.2$ with a sensitivity of $80 \%$, specificity of $87 \%$, positive predicted value of $86 \%$ and negative predicted value of $81 \%$. The eta protein also had high diagnostic odds ratio (26.1).

No correlation was found between serum levels of 14-3-3 eta and CRP nor ESR ( $p>0.05)$.

Conclusions: $14-3-3 \eta$ is a specific marker for RA that should be used in conjunction with RF and ACPA for diagnosis of the disease. However, no correlation was found between $14-3-3 \eta$ and markers of inflammation.

\section{REFERENCES}

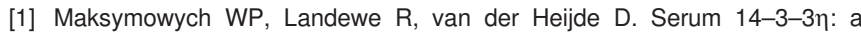
rheumatoid arthritis biomarker. Arthritis Rheum. 2011;63:358

[2] van Beers-Tas M, Marotta A, Maarten Boers M, Maksymowych W, van Schaardenburg D. Arthritis Research \& Therapy 2016;18:7.

[3] Aletaha D, Neogi T, Silman AJ, et al. Rheumatoid arthritis classification criteria: an American College of Rheumatology/European League Against Rheumatism collaborative initiative. Ann Rheum Dis. 2010;69(9):1580 1588.

[4] Altman R, Alarcón G, Appelrouth D, et al. The American College of Rheu matology criteria for the classification and reporting of osteoarthritis of the hand. Arthritis Rheum. 1990;33(11):1601-10.

Disclosure of Interest: None declared DOI: 10.1136/annrheumdis-2018-eular.4188 